\title{
Auditory evoked potential audiograms in post-settlement stage individuals of coral reef fishes
}

\author{
Orphal Colleye ${ }^{\mathrm{a}, *}$, Loïc Kéver ${ }^{\mathrm{a}}$, David Lecchini ${ }^{\mathrm{b}, \mathrm{c}}$, Laetitia Berten ${ }^{\mathrm{a}, \mathrm{b}}$, Eric Parmentier ${ }^{\mathrm{a}}$ \\ a Laboratoire de Morphologie Fonctionnelle et Evolutive, Université de Liège, Institut de chimie, Bât. B6C, Quartier Agora, Allée du six Août 15, B-4000 Liège, Belgium \\ b USR 3278 CNRS-EPHE-UPVD, Paris Sciences Lettres, CRIOBE, Moorea, French Polynesia \\ ' Laboratoire d'Excellence “CORAIL", Avenue Paul Alduy 58, 66860 Perpignan, France
}

\section{A R T I C L E I N F O}

\section{Article history:}

Received 8 October 2015

Received in revised form 11 April 2016

Accepted 19 May 2016

Available online 6 June 2016

\section{Keywords:}

Coral reef fishes

Auditory evoked potentials

Audiograms

Early life stages

Size groups

\begin{abstract}
A B S T R A C T
Just after the reef colonization, fish species could use the acoustic cue to settle on different suitable habitats. In the present study, we used the auditory evoked potential (AEP) technique to measure and compare the detection abilities in five coral reef fish species, with some of these species that are found in the same habitat. We also examined the effect of fish size on sensitivity at the species level. All studied species except one showed size-related changes in sensitivity characterized by either a decrease (i.e. higher AEP thresholds) or an increase (i.e. lower AEP thresholds) in detection abilities with increasing size. The interspecific comparison of audiograms revealed that some species are more sensitive than others in terms of sound pressure level and frequency detection.

Overall, this study indicates that the AEP threshold and the frequency bandwidth at early life stages may vary between and within fish species. The detection abilities are different in fish species that are not phylogenetically related, which might suggest that the establishment of their capabilities is not necessarily related to the reef conquest.
\end{abstract}

(c) 2016 Elsevier B.V. All rights reserved.

\section{Introduction}

The majority of coral reef fishes have a bipartite life cycle including a dispersive pelagic larval phase followed by sedentary demersal juvenile and adult phases associated with the coral reef environment (Leis, 1991; Leis and McCormick, 2002). The reef colonization usually occurs at night (Dufour and Galzin, 1993), and is quickly followed by the settlement on a suitable habitat (Lecchini, 2005). The recognition of the settlement sites would be based on different types of cues since sensory organs in fishes are known to be functional early in their development (Leis et al., 2002; Myrberg and Fuiman, 2002; Barth et al., 2015). Several studies have highlighted that settling fishes can detect and respond to reef sound (e.g. Leis et al., 2002, 2003; Simpson et al., 2004; Tolimieri et al., 2000, 2004; Leis and Lockett, 2005; Mann et al., 2007). However, understanding this process is more complicated than it appears. For example, the different settling fish species did not show the same attraction to sounds from different reef habitats (Parmentier et al., 2015). In addition, hearing research has shown that auditory abilities may change with fish growth. Audiograms of pre-settlement larvae and post-settlement juveniles have been measured in several pomacentrid species such as Stegastes partitus, Stegastes variabilis, Pomacentrus nagasakiensis and Abudefduf saxatilis (Kenyon, 1996; Wright et al., 2005; Egner and

\footnotetext{
* Corresponding author.

E-mail address: O.Colleye@ulg.ac.be (O. Colleye).
}

Mann, 2005). Differences in hearing abilities among different size classes have also been observed for other coral reef-dwelling species such as the carangid Caranx ignobilis, the serranid Epinephelus coioides, the polynemid Eleutheronema tetradactulum and the percichthyid Macquaria novemaculeata (Wright et al., 2011). In all these studies, an improvement in auditory abilities with fish size was observed (Wright et al., 2005, 2011). Such improvements mainly occurred at low frequencies $(<1000 \mathrm{~Hz})$, which resulted in a downward progression (i.e. more sensitive) of auditory thresholds with increasing size (see Egner and Mann, 2005; Wright et al., 2011). Furthermore, changes in hearing abilities may be related to the development of morphological adaptations. Some of the best-known examples were found in holocentrids and chaetodontids, in which rostral extensions of the swim bladder towards the otic capsule resulted in enhanced hearing (Coombs and Popper, 1979; Tricas and Boyle, 2015).

Generally speaking, fish audiograms are measured using the auditory evoked potential (AEP) technique (Kenyon et al., 1998). This electrophysiological technique is classically used to determine the auditory thresholds across a range of different frequencies. It is now clear that direct comparison of AEP audiograms from different laboratories is problematic because important variation in thresholds may result from different experimental conditions (Ladich and Fay, 2013). Here, AEP recordings were performed under the same experimental conditions. The present study aimed to compare AEP thresholds in five coral reef fish species from different families. Moreover, we examined any effect of 
fish size on the detection abilities at the species level by using different size groups. Ultimately, this study helped to determine which are the most sensitive species in terms of sound pressure level and frequency detection and how their sensitivity can be affected by fish size.

\section{Material and methods}

\subsection{Acquisition and maintenance of fishes}

A total of 84 individuals was purchased from a commercial supplier (De Jong Marinelife, Spijk, The Netherlands). These individuals belonged to different species: the Indo-Pacific sergeant damselfish Abudefduf vaigiensis Quoy \& Gaimard, 1825 (Pomacentridae), the convict surgeonfish Acanthurus triostegus Linnaeus, 1758 (Acanthuridae), the speckled butterflyfish Chaetodon citrinellus Cuvier, 1831 (Chaetodontidae), the white-banded triggerfish Rhinecanthus aculeatus Linnaeus, 1758 (Balistidae), and the shoulderbar soldierfish Myripristis kuntee Valenciennes, 1831 (Holocentridae). Each species was maintained in separate tanks $(1.2 \times 0.4 \times 0.6 \mathrm{~m})$ filled with saltwater maintained at $26{ }^{\circ} \mathrm{C}$. These tanks were equipped with a sand bottom and external filters. No internal filters or air stones were used in order to create a quiet acoustic environment. Fishes were kept under a 12:12 h L:D photoperiod and were fed with red blood worms twice a day. All fishes were held for 1 to 3 days before being tested. For experimental reasons, individuals of the five different species were divided into three size groups (i.e. small, medium and large; see Table 1).

\subsection{AEP thresholds measurement: experimental setup}

The AEP technique directly measures nerve impulses created in the eighth nerve and activity of the brainstem evoked by acoustic stimuli (Corwin et al., 1982). Presence or absence of response to sounds of different intensities and frequencies allows the measurement of AEP thresholds. The experimental setup was similar to that used for previous studies (Parmentier et al., 2009; Colleye et al., 2013). No anesthetics or neuromuscular-blocking drug were used during the AEP recordings. However, each fish was restrained in a custom-made harness in order to prevent electrode dislodging as well as body and tail movements while allowing normal ventilation. This mesh harness was closed dorsally and caudally with small pliers suspended from a steel frame. Three subdermal stainless steel needle electrodes (Rochester Electro-Medical, Lutz, FL, USA) were used for recording the AEP signal. These electrodes were coated with nail polish so that only $\sim 1 \mathrm{~mm}$ of metal was exposed at the tip. The recording electrode was inserted about 1-2 mm deep into the head over the otic region, the reference electrode was inserted into the epaxial musculature, and the ground electrode was placed in the tank water near the fish. All AEP recordings were carried out in a steel tube (1.2 $\mathrm{m}$ high, $22 \mathrm{~cm}$ diameter, $0.7 \mathrm{~cm}$ thickness) closed at the bottom with a square steel plate $(40 \times 40 \mathrm{~cm})$ and oriented vertically. The tube was filled with saltwater $\left(T=26^{\circ} \mathrm{C}\right)$ up to a height of

Table 1

Standard length (SL) of the different size groups in five coral reef fish species.

\begin{tabular}{|c|c|c|c|c|c|c|}
\hline \multirow[t]{3}{*}{ Species } & \multicolumn{6}{|l|}{ Group } \\
\hline & \multicolumn{2}{|c|}{ Small size } & \multicolumn{2}{|c|}{ Middle size } & \multicolumn{2}{|l|}{ Large size } \\
\hline & $\mathrm{SL}(\mathrm{mm})$ & $n$ & $\mathrm{SL}(\mathrm{mm})$ & $n$ & $\mathrm{SL}(\mathrm{mm})$ & $n$ \\
\hline Abudefduf vaigiensis & $28-37$ & 9 & $54-59$ & 5 & $60-70$ & 5 \\
\hline Acanthurus triostegus & $48-58$ & 4 & $63-69$ & 8 & $70-78$ & 7 \\
\hline Chaetodon citrinellus & $36-48$ & 4 & $57-69$ & 7 & $76-85$ & 3 \\
\hline Rhinecanthus aculeatus & $38-44$ & 7 & $47-54$ & 7 & $60-76$ & 3 \\
\hline Myripristis kuntee & $53-59$ & 5 & $67-88$ & 5 & $108-112$ & 5 \\
\hline
\end{tabular}

$n$, Number of individuals analyzed.
$1.12 \mathrm{~m}$, and the test fish was suspended $10 \mathrm{~cm}$ below the water surface and centered so that it was about $1 \mathrm{~m}$ above the loudspeaker (UW-30, Lubell Labs, Colombus, OH, USA) placed at the bottom of the experimental tank. The entire setup was enclosed in a walk-in soundproof booth (interior dimensions: $1.8 \times 1.8 \times 2.1 \mathrm{~m}$ ).

\subsection{Stimulus generation and AEP recordings}

The presentation of sound stimuli and the determination of thresholds followed the detailed description given by Parmentier et al. (2009). Stimuli were tone bursts of $50 \mathrm{~ms}$ in total duration gated with a Hanning window. The phase of the tone was alternated between presentations to minimize electrical artifacts from the recordings. During each trial, 14 different frequencies were presented: 150, 300, 600, 900, $1200,1500,1800,2100,2400,2700,3000,3300,3600$ and $3900 \mathrm{~Hz}$; these frequencies covered the expected range of hearing of the studied species (e.g. Coombs and Popper, 1979; Egner and Mann, 2005; Tricas and Boyle, 2015). Sound levels at each frequency were presented at up to $162 \mathrm{~dB}_{\text {rms }}$ re $1 \mu \mathrm{Pa}$ and were attenuated in $6 \mathrm{~dB}$ steps until a threshold level was determined. Evoked potentials recorded by the electrode were fed through a TDT HS4-DB4 amplifier (10,000 gain) connected to an RP2.1, routed into the computer and averaged by BioSig software. To measure the evoked response at each level of each frequency, the signal was presented up to a total of 500 times. Sound levels produced by the loudspeaker were calibrated with a Brüel and Kjær (Nærum, Denmark) hydrophone (model \#8101; sensitivity - $184 \mathrm{~dB}$ re $1 \mathrm{~V} / 1 \mu \mathrm{Pa}$; frequency response $0.1 \mathrm{~Hz}$ to $200 \mathrm{kHz}$ ) placed in the experimental tank at the position normally occupied by the fish head. The hydrophone was connected to a calibrated Brüel and Kjær 2610 amplifier that gave the absolute sound pressure level at all frequencies and intensity levels tested.

A 4096-point Fast Fourier Transform (FFT) was used to analyze the averaged AEP waveforms in the frequency domain. An auditory response was determined to be positive when the signal showed the presence of a peak at twice the stimulus frequency (e.g., $300 \mathrm{~Hz}$ peak when the signal played was $150 \mathrm{~Hz}$ ). The background level was estimated from the AEP power spectrum with a window of $100 \mathrm{~Hz}$ around the doubling frequency (Capser and Mann, 2006). Thresholds were determined by both the averaged AEP trace and power spectrum and were defined as the lowest sound level to show a repeatable AEP trace above the background noise, with an FFT peak at twice the stimulus frequency being at least $3 \mathrm{~dB}$ above the background level (Egner and Mann, 2005). Thresholds were expressed in terms of Sound Pressure Level (SPL).

In order to make sure that the recorded AEP traces were not artifacts, controls were run by testing dead fishes in the experimental setup. No responses were recorded with dead fishes (Fig. 1).

\subsection{Statistical analyses}

A Shapiro-Wilk test was used to test the normal distribution of acoustic data. Firstly, AEP thresholds were compared between the three size groups within each species. Two-way ANOVA with Tukey's multiple comparisons were performed to compare frequencies for which all size groups showed a positive response. In some cases, twoway ANOVA with Sidak's multiple comparisons were also performed because positive responses were observed at higher frequencies for only two size groups. Secondly, a two-way ANOVA was performed to compare AEP thresholds between the five species considering all data, regardless of the fish size. Results are expressed as means \pm standard error of the mean (S.E.M.).

Least-square linear regressions were used to examine changes in auditory abilities across standard length (SL) in the five species at all frequencies tested. The data used in theses analyses corresponded to the AEP thresholds measured for all individuals of the different size groups. Note that these data were graphically represented only for 


\section{Acanthurus triostegus}

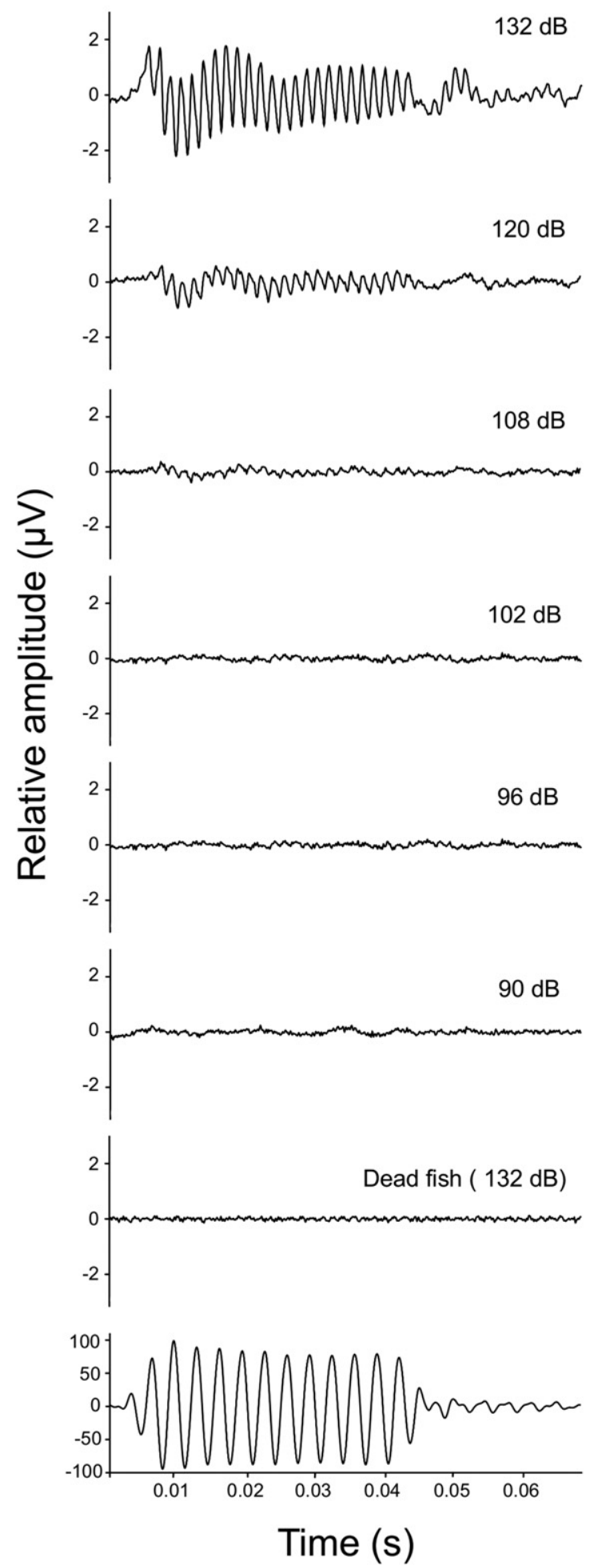

Chaetodon citrinellus
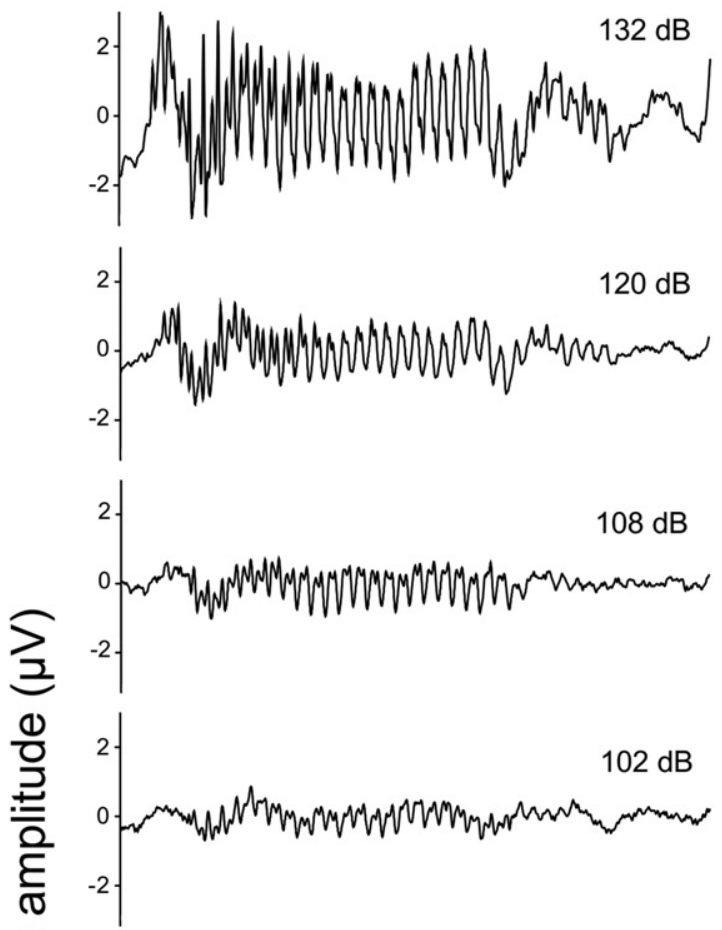

$96 \mathrm{~dB}$
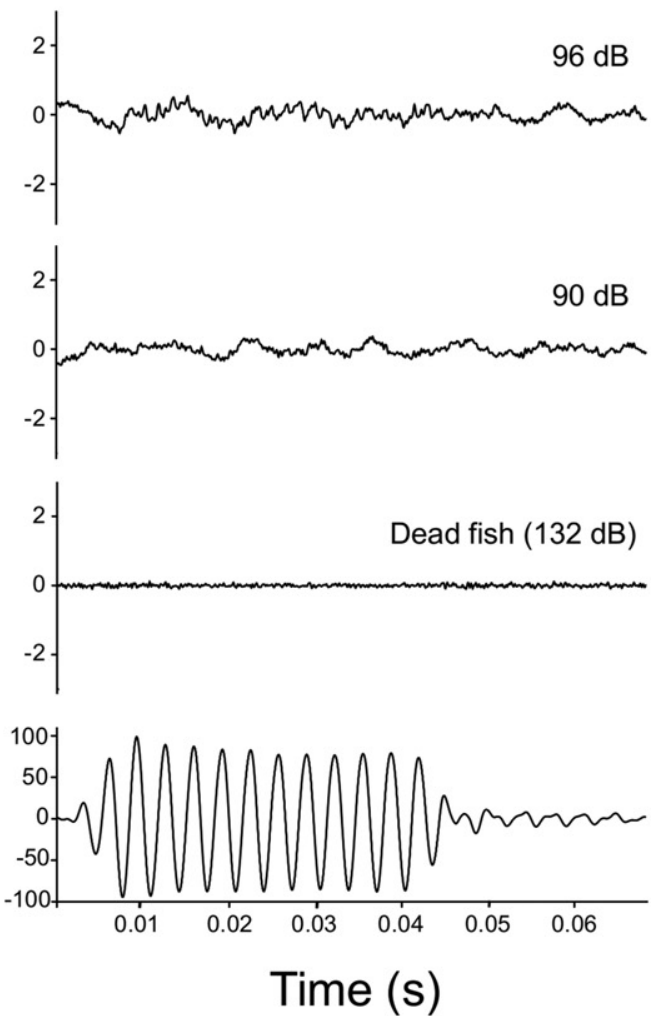

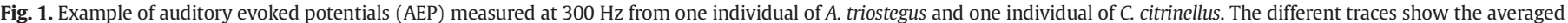

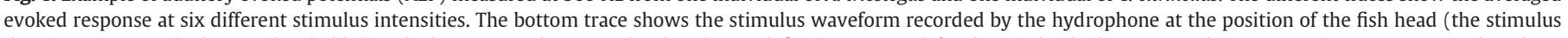

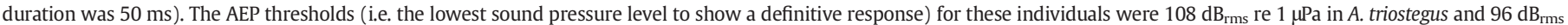
re $1 \mu \mathrm{Pa}$ in $C$. citrinellus. Note that no response occurred for any dead controls.

the butterflyfish $C$. citrinellus and the triggerfish $R$. aculeatus because they showed correlations between fish size and detection abilities for most of the frequencies tested.
All statistical analyses were performed with STATISTICA 9.1 (StatSoft, Tulsa, OK, USA) and GrafPad Prism 5 (GrafPad Software, Inc. USA). Significance level was determined at $p<0.05$. 


\section{Results}

Evoked potentials were obtained from all species tested. Whatever the species, representative AEP traces were similar in shape within a given test frequency across all individuals (Fig. 1). Waveforms produced in response to stimulus presentation decreased in magnitude as the SPL decreased, and were thus used to determine AEP thresholds (Fig. 1).

\subsection{Size-related intraspecific variation in auditory capabilities}

Audiograms of $A$. vaigiensis showed an increase in AEP thresholds with increasing frequencies. The lowest threshold was observed at $150 \mathrm{~Hz}$ for the small $(28-37 \mathrm{~mm}, n=9)$ and middle $(54-59 \mathrm{~mm}$, $n=5$ ) size groups, being respectively of $108 \pm 4 \mathrm{~dB}$ re $1 \mu \mathrm{Pa}$ and $115 \pm 6 \mathrm{~dB}$ re $1 \mu \mathrm{Pa}$. In the large (60-70 $\mathrm{mm}, n=5)$ size group, the lowest AEP threshold was at $300 \mathrm{~Hz}$ with $120 \pm 4 \mathrm{~dB}$ re $1 \mu \mathrm{Pa}$ (see Fig. 2A).
Threshold at $150 \mathrm{~Hz}$ was significantly lower for the small individuals than for the large ones (two-way ANOVA, d.f. $=71, p<0.05$; Fig. 2A). Likewise, auditory thresholds were significantly different at $900 \mathrm{~Hz}$ between the small and middle size groups, with a lower threshold observed for the smaller fishes (Fig. 2A). No significant differences between size groups were observed at 300 and $600 \mathrm{~Hz}$ (Fig. 2A). Although positive responses were observed up to $1800 \mathrm{~Hz}$ for the small size group, comparison of auditory thresholds at frequencies above $900 \mathrm{~Hz}$ was not possible since only one fish from the medium size group was able to detect sounds at $1200 \mathrm{~Hz}$, and only one fish from the large size group at $1500 \mathrm{~Hz}$. Correlation analyses revealed a significant increase in AEP thresholds with increasing size only at $150 \mathrm{~Hz}$ ( $y=$ $0.3474 \times+97.16 ; r^{2}=0.46, p<0.05$ ).

The overall audiogram in $A$. triostegus showed the same tendency as the one observed for A. vaigiensis, with an increase in AEP thresholds with increasing frequencies. However, the small (48-58 mm, $n=4)$
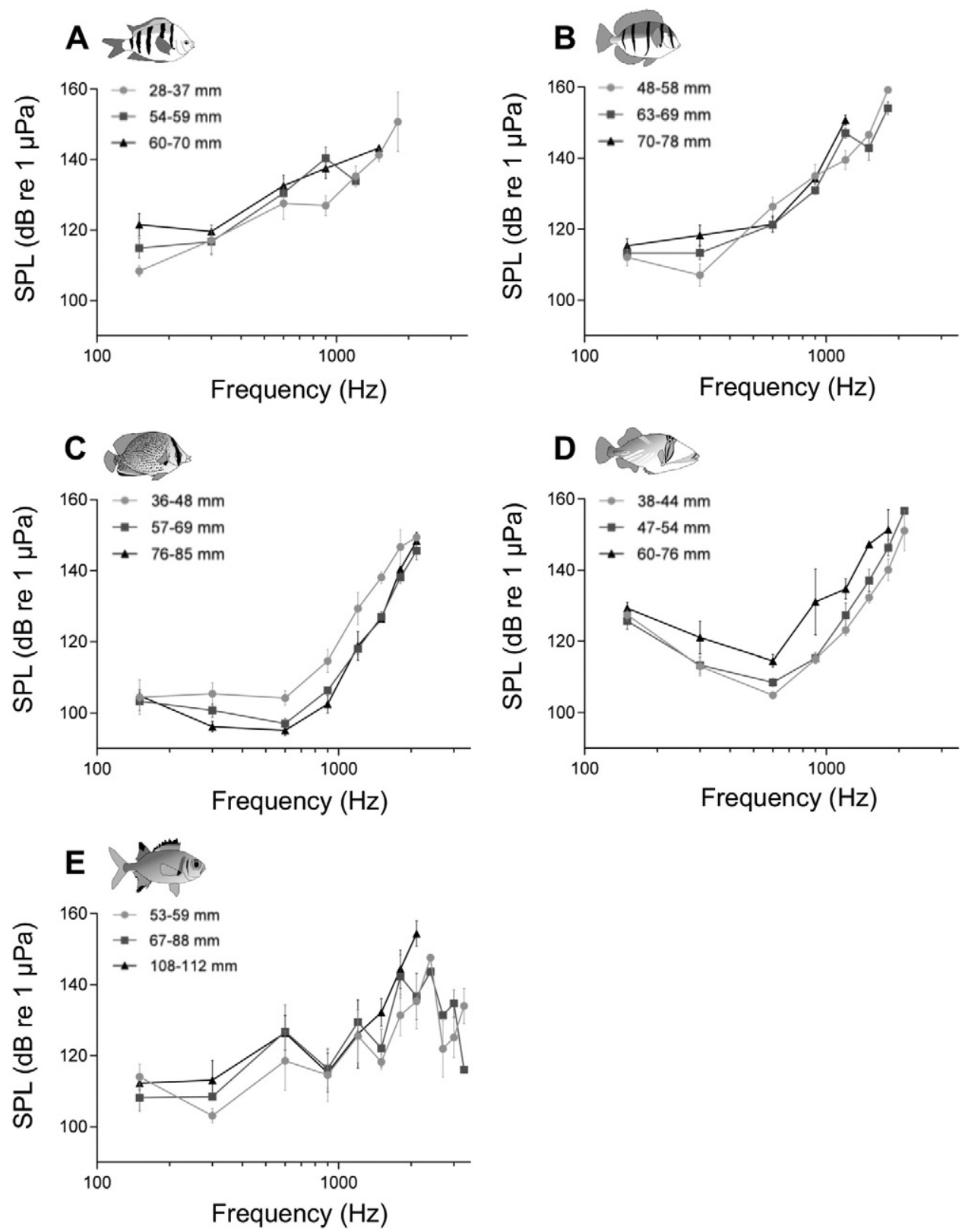

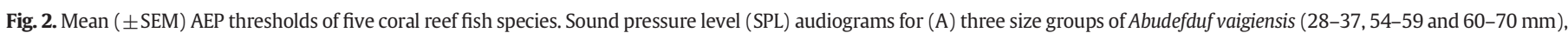

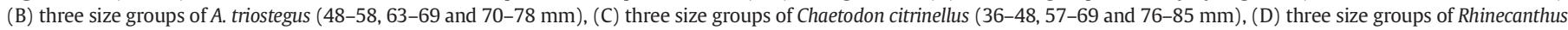

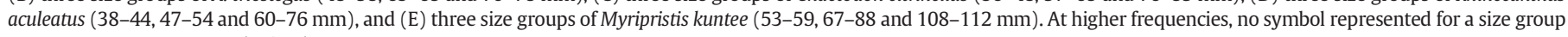
means no responses were obtained. 
size group showed a slight decrease in thresholds from 150 to $300 \mathrm{~Hz}$, with the lowest AEP threshold observed at $300 \mathrm{~Hz}$ (see Fig. 2B). Thus, the evoked response of the small size group at $300 \mathrm{~Hz}$ was significantly better than the one of the large (70-78 $\mathrm{mm}, n=7$ ) size group (two-way ANOVA, d.f. $=94, p<0.05$ ). No significant difference was found at 150 , 600 and $900 \mathrm{~Hz}$ among the three size groups. At $1200 \mathrm{~Hz}$, the small size group showed an auditory threshold significantly lower than the one of both the middle (63-69 $\mathrm{mm}, n=8$ ) and large size groups (two-way ANOVA, d.f. $=94, p<0.05)$. The large size group was unable to detect frequencies above $1200 \mathrm{~Hz}$, whereas positive responses at 1500 and $1800 \mathrm{~Hz}$ were recorded for the small $(n=2)$ and the middle $(n=4)$ size groups (Fig. 2B). In addition, a positive correlation between AEP thresholds and fish size was observed at $300 \mathrm{~Hz} \quad(y=$ $\left.0.4457 x+84.46 ; r^{2}=0.25, p<0.05\right)$ and $1200 \mathrm{~Hz}(y=$ $\left.0.5557 x+110.2 ; r^{2}=0.64, p<0.05\right)$.

Generally speaking, audiograms in C. citrinellus were similarly shaped, whatever the size group (Fig. 2C). They showed a slight decrease in AEP thresholds from $150 \mathrm{~Hz}$ to $600 \mathrm{~Hz}$ for the two larger size groups (middle size: $57-69 \mathrm{~mm}, n=7$; large size: 76-85 mm, $n=3$ ), whereas the small size group ( $36-48 \mathrm{~mm}, n=4$ ) had similar detection abilities from 150 to $600 \mathrm{~Hz}$. The lowest AEP threshold was observed at $600 \mathrm{~Hz}$ for each size group, being around $105 \mathrm{~dB}$ re $1 \mu \mathrm{Pa}$ for the small size group, at $97 \pm 4 \mathrm{~dB}$ re $1 \mu \mathrm{Pa}$ for the middle size group, and at $95 \pm 3 \mathrm{~dB}$ re $1 \mu \mathrm{Pa}$ for the large size class (Fig. 2C). Then, audiograms showed a high increase in auditory thresholds from 600 to $2100 \mathrm{~Hz}$ for all size groups (Fig. 2C). No significant differences between the three size groups were observed for frequencies below $900 \mathrm{~Hz}$. On the other hand, specimens from the small size group had a significantly higher auditory threshold than the middle and large size groups at 900, 1200, 1500 and $1800 \mathrm{~Hz}$ (see Table 2). Comparison of auditory thresholds at $2100 \mathrm{~Hz}$ between the three size groups was not possible because only one individual from the small size group showed a positive response. Thereby, a Sidak's multiple comparison between the two larger size groups was performed but it showed no significant difference at this frequency. Linear regressions showed that auditory thresholds were negatively correlated with fish size at all tested frequencies except at 150 and $2100 \mathrm{~Hz}$, which highlighted an increase in detection abilities with increasing size (Fig. 3).

AEP thresholds were also compared between three size groups (small size: $38-44 \mathrm{~mm}, n=7$; middle size: $47-54 \mathrm{~mm}, n=7$; large size: $60-76 \mathrm{~mm}, n=3$ ) in $R$. aculeatus. Whatever the size group, audiograms were similarly shaped with decreasing AEP thresholds from 150 to $600 \mathrm{~Hz}$, which corresponds to the lowest auditory threshold for all size groups, and then followed by an increase in auditory thresholds until $1800 \mathrm{~Hz}$ for the large size group, and until $2100 \mathrm{~Hz}$ for the two smaller size groups (see Fig. 2D). No significant difference was observed at $150,300,600,1200$ and $1800 \mathrm{~Hz}$. On the other hand, the largest size group was significantly different from the two others at $900 \mathrm{~Hz}$, showing a higher auditory threshold (two-way ANOVA, d.f. $=107$, $p<0.05$; see Fig. 2D). Likewise, the small size group was significantly different from the large one at $1500 \mathrm{~Hz}$, showing better detection abilities (two-way ANOVA, d.f. $=107, p<0.05$; see Fig. 2D). No comparison of auditory thresholds was performed at $2100 \mathrm{~Hz}$ because positive responses were obtained only for two individuals from the smallest size group and one specimen from the middle one. Linear regressions showed that auditory thresholds were positively correlated with fish size at all tested frequencies except at $150 \mathrm{~Hz}$, which highlighted a decrease in detection abilities with increasing size (Fig. 4).

Comparison of AEP thresholds between the three size groups (small size: $53-59 \mathrm{~mm}, n=5$; middle size: $67-88 \mathrm{~mm}, n=5$; large size: $108-$ $112 \mathrm{~mm}, n=5$ ) of $M$. kuntee showed no significant differences for frequencies between 150 and $2100 \mathrm{~Hz}$ (two-way ANOVA, $p>0.05$; see Fig. 2E). No response was observed for the largest size group at frequencies above $2100 \mathrm{~Hz}$. The small and middle size groups showed positive responses to frequencies up to $3300 \mathrm{~Hz}$, with no significant differences (two-way ANOVA, Sidak's multiple comparisons, $p>0.05$; see Fig. 2E). Overall, the lowest AEP threshold was observed at $150 \mathrm{~Hz}$, except for the small size group $(300 \mathrm{~Hz})$, and audiograms were punctuated by several ups and downs of auditory thresholds (Fig. 2E).

\subsection{Interspecific variation in hearing abilities}

Comparison of auditory abilities among all species revealed significant differences at different frequencies (Table 3). For example, $A$. vaigiensis and $A$. triostegus showed similar auditory thresholds at all frequencies except at $600 \mathrm{~Hz}(131 \pm 5 \mathrm{~dB}$ re $1 \mu \mathrm{Pa}$ vs $121 \pm 3 \mathrm{~dB}$ re $1 \mu \mathrm{Pa}$, $p<0.05$; see Table 3 ) and $1200 \mathrm{~Hz}(134 \pm 6 \mathrm{~dB}$ re $1 \mu \mathrm{Pa}$ vs $148 \pm 3 \mathrm{~dB}$ re $1 \mu \mathrm{Pa}, p<0.05$; see Table 3 ), whereas A. vaigiensis and C. citrinellus exhibited significantly different auditory thresholds at all frequencies except $1800 \mathrm{~Hz}(151 \pm 13 \mathrm{~dB}$ re $1 \mu \mathrm{Pa}$ vs $140 \pm 8 \mathrm{~dB}$ re $1 \mu \mathrm{Pa}, p>0.05$; see Table $3)$. The lowest AEP threshold was observed at $600 \mathrm{~Hz}$ for both $C$. citrinellus (99 $\pm 5 \mathrm{~dB}$ re $1 \mu \mathrm{Pa}$; Fig. 5 ) and $R$. aculeatus ( $109 \pm 6 \mathrm{~dB}$ re $1 \mu \mathrm{Pa}$; Fig. 5), at $300 \mathrm{~Hz}$ for $M$. kuntee ( $109 \pm 8 \mathrm{~dB}$ re $1 \mu \mathrm{Pa}$; Fig. 5), and at $150 \mathrm{~Hz}$ for $A$. vaigiensis ( $113 \pm 8 \mathrm{~dB}$ re $1 \mu \mathrm{Pa}$; Fig. 5$)$ and $A$. triostegus ( $114 \pm 5 \mathrm{~dB}$ re $1 \mu \mathrm{Pa}$; Fig. 5). Moreover, $C$. citrinellus exhibited the lowest auditory threshold for frequencies below $1200 \mathrm{~Hz}$ (Fig. 5). Although $M$. kuntee showed the lowest auditory threshold for frequencies above $1200 \mathrm{~Hz}$ (Fig. 5), it was not significantly different from $A$. vaigiensis, $C$. citrinellus and $R$. aculeatus (Table 3 ). In addition, M. kuntee was the only one species able to detect acoustic stimuli at frequencies above $2100 \mathrm{~Hz}$ (Fig. 5).

\section{Discussion}

Electrophysiological techniques such as the AEP recordings measure the neural activity of the whole auditory pathway (from the inner ear up to the midbrain or forebrain) in response to acoustic stimuli (Corwin et al., 1982; Kenyon et al., 1998). The majority of AEP recordings being typically conducted in small tanks, the particle motion component is important close to the sound source (the near field), which may also include lateral line inputs at lower frequencies (Higgs and Radford, 2013). Audiograms at lower frequencies should thus be interpreted as multimodal responses since both the inner ear and the canal neuromast hair cells can be stimulated during the AEP recordings

Table 2

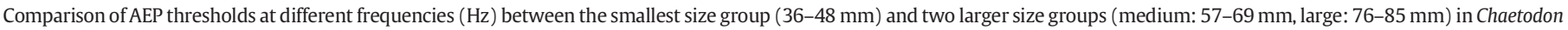
citrinellus.*, **

\begin{tabular}{|c|c|c|c|c|c|c|c|c|c|c|c|c|c|c|}
\hline & \multicolumn{7}{|c|}{ Middle size $(n=7)$} & \multicolumn{7}{|c|}{ Large size $(n=3)$} \\
\hline & $\begin{array}{l}150 \\
(\mathrm{~Hz})\end{array}$ & $\begin{array}{l}300 \\
(\mathrm{~Hz})\end{array}$ & $\begin{array}{l}600 \\
(\mathrm{~Hz})\end{array}$ & $\begin{array}{l}900 \\
(\mathrm{~Hz})\end{array}$ & $\begin{array}{l}1200 \\
(\mathrm{~Hz})\end{array}$ & $\begin{array}{l}1500 \\
(\mathrm{~Hz})\end{array}$ & $\begin{array}{l}1800 \\
(\mathrm{~Hz})\end{array}$ & $\begin{array}{l}150 \\
(\mathrm{~Hz})\end{array}$ & $\begin{array}{l}300 \\
(\mathrm{~Hz})\end{array}$ & $\begin{array}{l}600 \\
(\mathrm{~Hz})\end{array}$ & $\begin{array}{l}900 \\
(\mathrm{~Hz})\end{array}$ & $\begin{array}{l}1200 \\
(\mathrm{~Hz})\end{array}$ & $\begin{array}{l}1500 \\
(\mathrm{~Hz})\end{array}$ & $\begin{array}{l}1800 \\
(\mathrm{~Hz})\end{array}$ \\
\hline $\begin{array}{l}\text { Small size }(n= \\
\text { 4) }\end{array}$ & NS & NS & NS & $*$ & $* *$ & $* *$ & * & NS & NS & NS & $* *$ & * & $*$ & NS \\
\hline
\end{tabular}

$n$, Number of individuals analyzed; NS, Non-Significant differences. Results refer to two-way ANOVA with Tukey's multiple comparisons.

* $p<0.05$.

** $p<0.01$. 


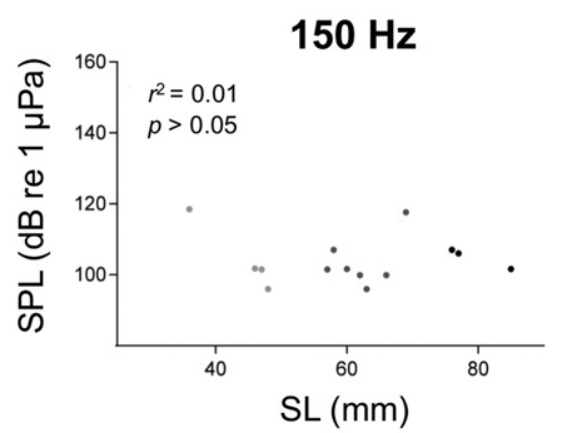

$600 \mathrm{~Hz}$

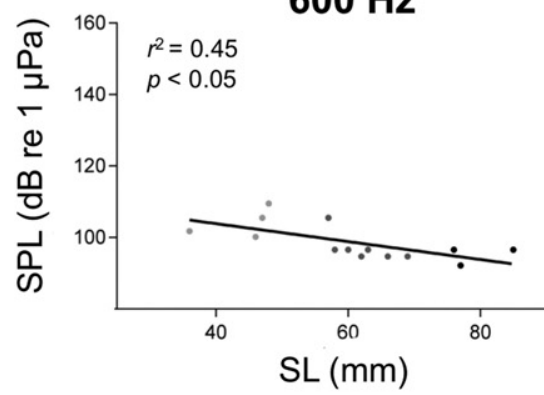

$1200 \mathrm{~Hz}$

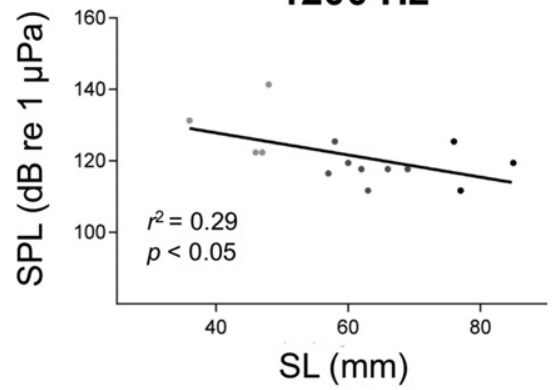

$1800 \mathrm{~Hz}$

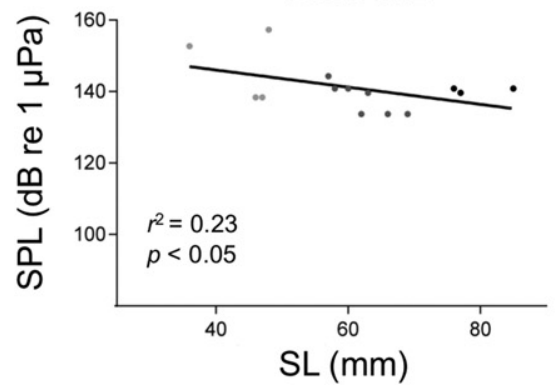

$300 \mathrm{~Hz}$

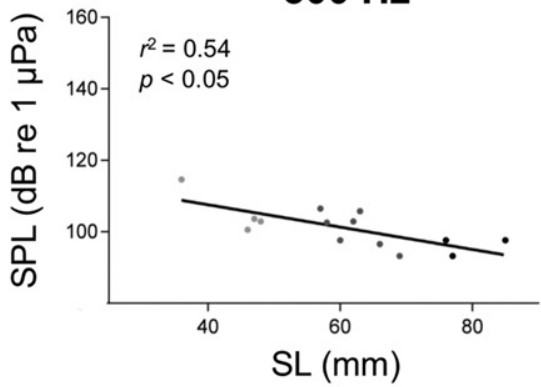

\section{$900 \mathrm{~Hz}$}

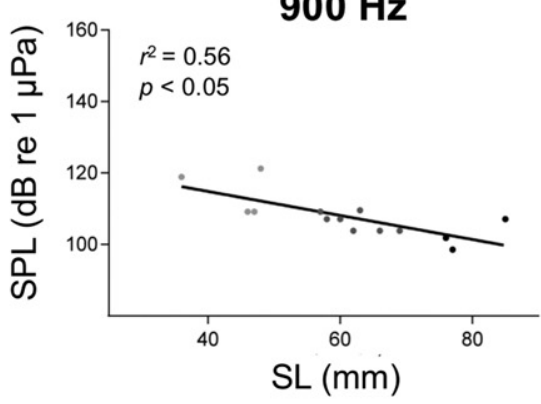

$1500 \mathrm{~Hz}$

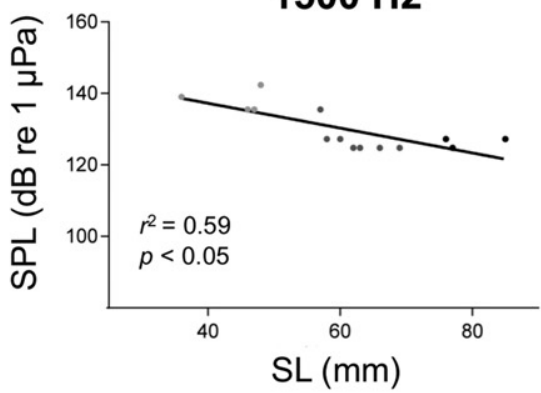

$2100 \mathrm{~Hz}$

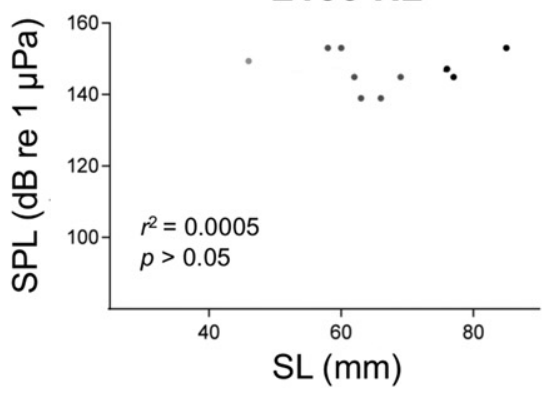

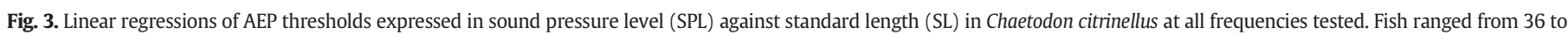

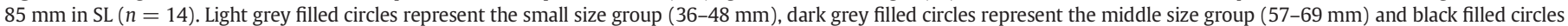

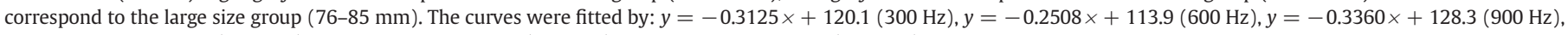
$y=-0.3096 x+140.2(1200 \mathrm{~Hz}), y=-0.3476 x+151.1(1500 \mathrm{~Hz}), y=-0.2400 x+155.6(1800 \mathrm{~Hz})$.

(Higgs and Radford, 2013). Given that no experimental manipulation was performed in the present study to test the contribution of the lateral line system, our audiograms cannot be interpreted solely as the result of an evoked response from the auditory hair cells, especially at lower frequencies $(\leq 200 \mathrm{~Hz})$. For this reason, a lower AEP threshold at these lower frequencies reflects a higher sensitivity to the near field component of the acoustic environment but not necessarily a better hearing sensitivity.

Overall, our results showed size-related changes in sensitivity at the species level that are characterized by a decrease in detection abilities with increasing size, except in the butterflyfish $C$. citrinellus. The interspecific comparison of audiograms revealed that $C$. citrinellus and M. kuntee have the best detection abilities in terms of AEP thresholds and frequency range, respectively (Fig. 5).

\subsection{Size-related variation in hearing abilities at the species level}

Changes in hearing abilities in relation to fish size have already been observed in different species, but results were somewhat conflicting. Indeed, AEP audiograms showed an improvement in hearing abilities with increasing size in the carangid Caranx ignobilis, the serranid Epinephelus coioides, the polynemid Eleutheronema tetradactylum and the 


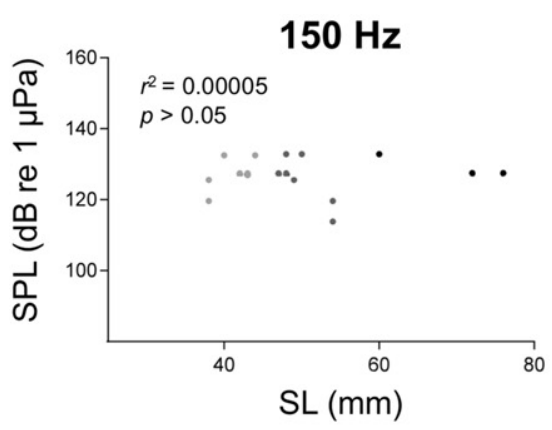

\section{$600 \mathrm{~Hz}$}
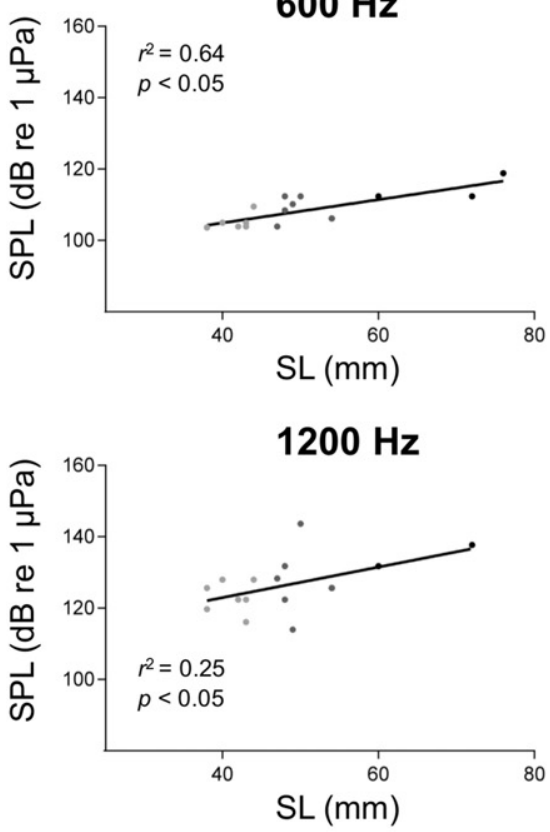

$1800 \mathrm{~Hz}$

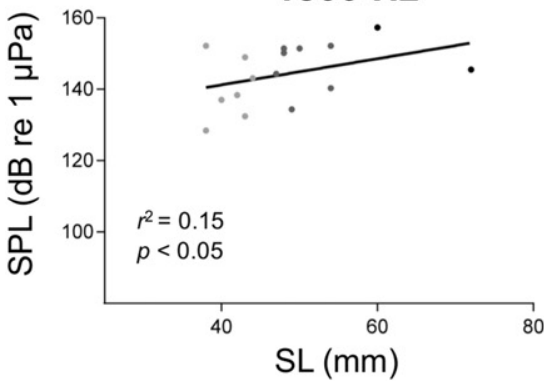

$300 \mathrm{~Hz}$
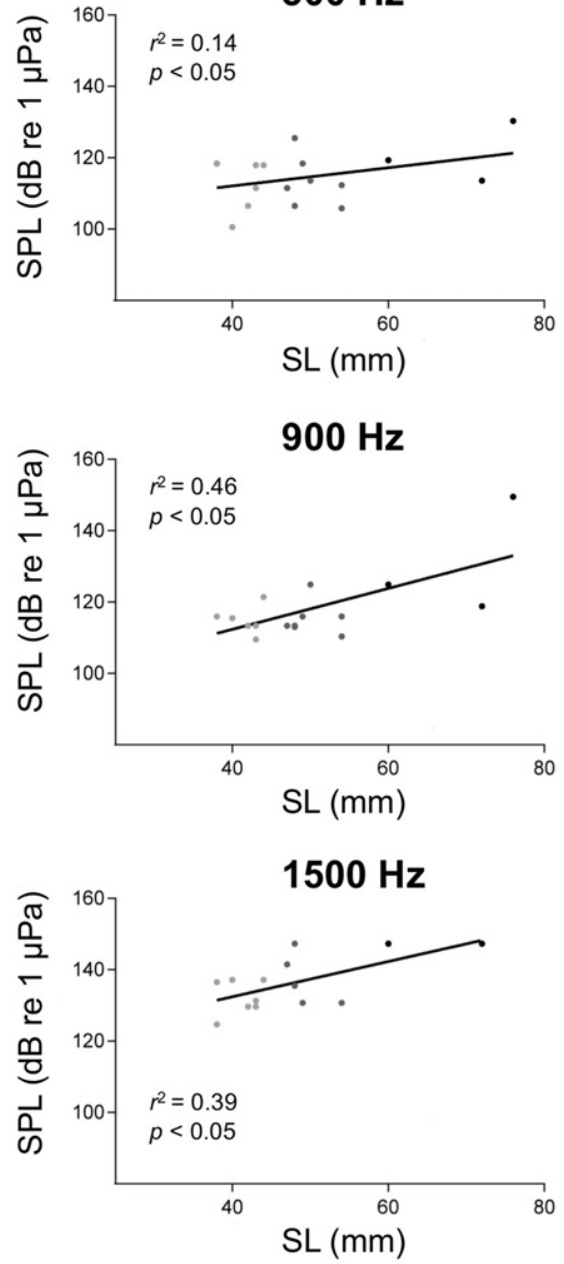

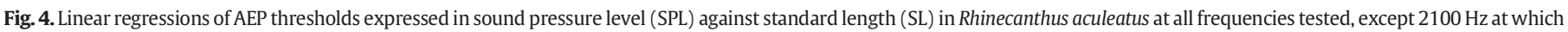

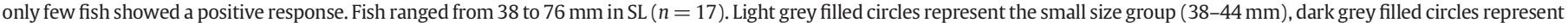

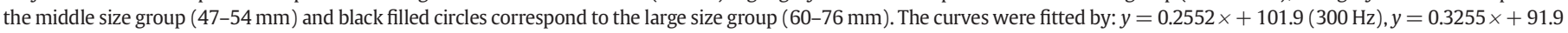
$(600 \mathrm{~Hz}), y=0.5726 x+89.47(900 \mathrm{~Hz}), y=0.4274 x+105.9(1200 \mathrm{~Hz}), y=0.4937 x+112.7(1500 \mathrm{~Hz}), y=0.3664 x+126.6(1800 \mathrm{~Hz})$.

percichthyid Macquaria novemaculeata (Wright et al., 2011). However, the opposite result was also observed since AEP audiograms showed a decrease in hearing sensitivity with increasing size in the pomacentrid Abudefduf saxatilis (Egner and Mann, 2005).

Generally speaking, the present study including five coral reef fish species belonging to different families has led to similar conflicting results since all species did not show the same size-related variation in detection abilities. For example, an increase in detection abilities (i.e. lower detection thresholds) with increasing size was observed in $C$. citrinellus (Fig. 3), whereas a decrease in detection abilities (i.e. higher detection thresholds) with increasing size was observed in $R$. aculeatus at all frequencies tested (Fig. 4). The same tendency was also observed in A. triostegus and in A. vaigiensis but only at some frequencies tested.
Interestingly, the results about $A$. vaigiensis were roughly similar to the overall audiogram of $A$. saxatilis (Egner and Mann, 2005). However, Egner and Mann (2005) observed size-related differences in the range of detected frequencies: individuals $<30 \mathrm{~mm}$ were able to detect frequencies up to $1200 \mathrm{~Hz}$, while it went up to $1400 \mathrm{~Hz}$ for individuals between 30 and $50 \mathrm{~mm}$, and up to $1600 \mathrm{~Hz}$ for individuals $>50 \mathrm{~mm}$. This was not the case in our study since the small size group $(28-37 \mathrm{~mm})$ was able to detect frequencies up to $1800 \mathrm{~Hz}$, whereas the large and medium size groups could not detect frequencies above $1500 \mathrm{~Hz}$ and $1200 \mathrm{~Hz}$, respectively (Fig. 2A). Finally, no significant difference in AEP thresholds with fish size was observed in M. kuntee.

It is quite difficult to give clear morphological reasons to these sizerelated changes in detection abilities since examination of the 
Table 3

Comparison of mean AEP thresholds at different frequencies among five coral reef fish species.

\begin{tabular}{|c|c|c|c|c|c|}
\hline & $\begin{array}{l}\text { Frequency } \\
(\mathrm{Hz})\end{array}$ & A. vaigiensis & A. triostegus & C. citrinellus & R. aculeatus \\
\hline \multirow[t]{7}{*}{ A. triostegus } & 150 & NS & - & - & - \\
\hline & 300 & NS & - & - & - \\
\hline & 600 & 0.045 & - & - & - \\
\hline & 900 & NS & - & - & - \\
\hline & 1200 & 0.018 & - & - & - \\
\hline & 1500 & NS & - & - & - \\
\hline & 1800 & NS & - & - & - \\
\hline \multirow[t]{7}{*}{ C. citrinellus } & 150 & 0.008 & 0.006 & - & - \\
\hline & 300 & $<0.0001$ & 0.0001 & - & - \\
\hline & 600 & $<0.0001$ & $<0.0001$ & - & - \\
\hline & 900 & $<0.0001$ & $<0.0001$ & - & - \\
\hline & 1200 & 0.003 & $<0.0001$ & - & - \\
\hline & 1500 & 0.031 & NS & - & - \\
\hline & 1800 & NS & 0.002 & - & - \\
\hline \multirow[t]{7}{*}{ R. aculeatus } & 150 & $<0.0001$ & $<0.0001$ & $<0.0001$ & - \\
\hline & 300 & NS & NS & $<0.0001$ & - \\
\hline & 600 & $<0.0001$ & $<0.0001$ & 0.003 & - \\
\hline & 900 & $<0.0001$ & $<0.0001$ & 0.002 & - \\
\hline & 1200 & NS & $<0.0001$ & NS & - \\
\hline & 1500 & NS & NS & NS & - \\
\hline & 1800 & NS & 0.045 & NS & - \\
\hline \multirow[t]{7}{*}{ M. kuntee } & 150 & NS & NS & 0.005 & $<0.0001$ \\
\hline & 300 & 0.015 & NS & NS & NS \\
\hline & 600 & NS & NS & $<0.0001$ & $<0.0001$ \\
\hline & 900 & $<0.0001$ & $<0.0001$ & NS & NS \\
\hline & 1200 & NS & $<0.0001$ & NS & NS \\
\hline & 1500 & NS & 0.002 & NS & 0.003 \\
\hline & 1800 & NS & 0.0001 & NS & NS \\
\hline
\end{tabular}

NS, Non-Significant differences. Results refer to two-way ANOVA with Tukey's multiple comparisons.

morphology of the hearing system was not conducted in the present study. One possible explanation for the improvement in detection abilities with increasing size observed in C. citrinellus could be due to a morphological change of the laterophysic connection (LC) during fish growth. All butterflyfishes of the genus Chaetodon are known to possess a LC, which connects (partially or totally) bilateral anterior extensions of the swim bladder (commonly named "swim bladder horns") to a medial opening in the supracleithral lateral line canal, forming a pseudootophysic connection (Webb, 1998; Webb and Smith, 2000; Smith et al., 2003; Webb et al., 2006). This LC was thought to enhance the sound detection by transmitting the sound pressure stimuli to the lateral line via the swim bladder horns, and converting the sound pressure to fluid flow through a laterophysic tympanum (Webb, 1998; Webb and Smith, 2000; Smith et al., 2003; Webb et al., 2006). Surprisingly, Webb et al. (2012) did not observe a relationship between fish size and

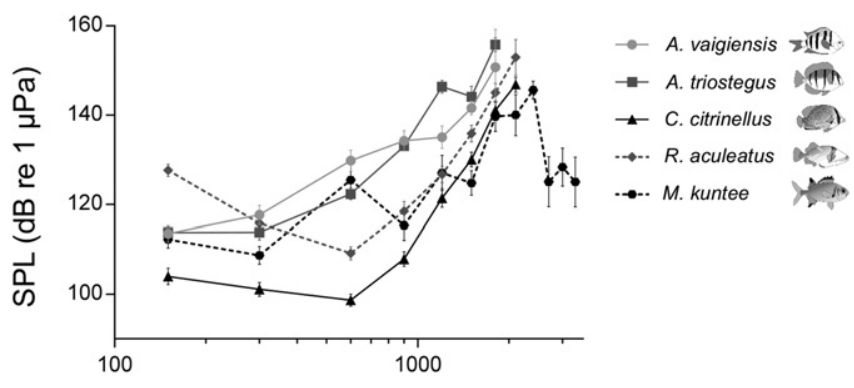

Frequency $(\mathrm{Hz})$

Fig. 5. Mean ( \pm SEM) AEP thresholds of five coral reef fish species. Sound pressure level (SPL) audiograms for (A) Abudefduf vaigiensis ( $n=19$; SL $=28-70 \mathrm{~mm})$, (B) Acanthurus triostegus ( $n=19 ; \mathrm{SL}=48-78 \mathrm{~mm}),(\mathrm{C})$ Chaetodon citrinellus ( $n=14$; $\mathrm{SL}=36-85 \mathrm{~mm})$, (D) Rhinecanthus aculeatus $(n=17 ; \mathrm{SL}=38-76 \mathrm{~mm})$ and (E) Myripristis kuntee $(n=15 ; \mathrm{SL}=53-112 \mathrm{~mm})$. At frequencies above $1800 \mathrm{~Hz}$, no symbol represented for some species means no responses were obtained. hearing abilities in Chaetodon ocellatus but they measured AEP audiograms with individuals ranged in size from 21 to $31 \mathrm{~mm}$ (vs 36$85 \mathrm{~mm}$ in the present study). The medial opening in the supracleithral lateral line canal in C. ocellatus is present in 14-17 mm individuals. However, the swim bladder horns are formed when specimens reach the size of 25 to $29 \mathrm{~mm}$, which roughly corresponded to their sample size (Webb et al., 2012). Although the distance between the swim bladder horns and both the medial opening in the supracleithral lateral line canal and the inner ear did not change appreciably during growth in $C$. ocellatus (Webb et al., 2012), it might be different in the case of $C$. citrinellus due to a different development of the LC system. Webb et al. (2006) found an interspecific variation in LC morphology with two LC types (direct and indirect) that differ depending on whether or not the swim bladder horns are in direct contact with the medial opening in the supracleithral lateral line canal. There also exist two variants of a direct LC and four variants of an indirect LC. These variants are defined by a combination of features (i.e. soft tissue anatomy, horn length [long/ short], horn diameter [wide/narrow], number of swim bladder chambers [one/two], and presence/absence of mucoid connective tissue in the medial opening in the supracleithrum), which is supposed to have consequences for the bioacoustics of the system (Webb et al., 2006). Taking all this into consideration, it is likely that the enhanced acoustic sensitivity with increasing size in C. citrinellus may be related to the spatial relationships between the supracleithral lateral line canal, the swim bladder and the development of the horns, and the inner ear. The swim bladder horns might be brought closer to the otic capsule with increasing size. For example, displacement of gas from the swim bladder horns in two Chaetodon species is known to decrease hearing sensitivity (Tricas and Boyle, 2015).

On another note, the decrease in detection abilities with increasing size observed in $R$. aculeatus could be due to the closer proximity of the swim bladder to the inner ear in the smallest individuals. This morphological configuration might allow the bladder to act as a more pronounced amplifier at certain frequencies (see Egner and Mann, 2005). In both cases, further investigations are needed to find out the true morphological mechanisms behind these changes in AEP thresholds. In addition, the lower thresholds exhibited by the smallest size group of $A$. vaigiensis and $A$. triostegus at some frequencies could be explained by variation in electrode placement during AEP recordings. It is likely that the electrode was closer to the brain in smaller individuals, which may result in a larger AEP response in some of the smaller individuals compared to larger ones (see Egner and Mann, 2005).

\subsection{Interspecific differences in auditory capabilities}

Comparison of AEP audiograms showed differences in mean thresholds among all studied species at several frequencies tested (Table 3, Fig. 5). Previous studies have already measured behavioral audiograms in holocentrids (Tavolga and Wodinsky, 1963; Coombs and Popper, 1979), as well as AEP audiograms in a few pomacentrids (Egner and Mann, 2005; Wright et al., 2005; Wysocki et al., 2009) and chaetodontids (Webb et al., 2012; Tricas and Boyle, 2015). However, direct comparison of these studies with our AEP traces can be irrelevant because audiograms produce very different results depending on the methodology used (i.e. behavioral vs electrophysiological measures; Sisneros et al., 2016) and the acoustic environment under which they are measured (Ladich and Fay, 2013). C. citrinellus showed the lowest AEP threshold for frequencies below $1200 \mathrm{~Hz}$ while $M$. kuntee exhibited the widest range of detected frequencies (Fig. 5). Morphological adaptations (i.e. hearing specializations) could explain why these two species exhibited the best detection abilities. All members the genus Chaetodon have the laterophysic connection (Webb, 1998; Webb and Smith, 2000; Smith et al., 2003; Webb et al., 2006). Recently, Tricas and Boyle (2015) clearly demonstrated the action of the LC system on auditory abilities by comparing butterflyfish species with or without swim bladder horns and LC. This system enables a better hearing sensitivity characterized 
by a lower detection thresholds and an extended frequency range (Tricas and Boyle, 2015). Furthermore, all species from the Holocentridae subfamily Myripristinae (e.g. the soldierfish M. kuntee) possess an otophysic connection; another hearing specialization connecting anterior swim bladder horns with the otic capsule of the inner ear (Coombs and Popper, 1979; Braun and Grande, 2008). The otophysic connection enhances the hearing sensitivity, hence a broad frequency range of hearing and a low auditory threshold.

Our data on the detection abilities in five coral reef fish species might offer new perspectives about the use of the acoustic cue to detect a suitable settlement site. These five species showed significant differences in their AEP threshold and frequency bandwidth, but they are all able to settle on patch reefs located in Moorea Island (Dufour and Galzin, 1993; Lecchini et al., 2006). Recently, Bertucci et al. (2015) measured underwater sound signatures of different reef habitats in this area and they observed that the inner reef crest, the fringing reef and the barrier reef had similar spectral patterns with a maximum peak of sound intensities around $200 \mathrm{~Hz}$. This peak intensity occurred at a frequency near the lowest AEP threshold of the studied species (Fig. 5). However, recent playback experiments indicated that larvae of $R$. aculeatus and $M$. kuntee are preferentially attracted by barrier reef and fringing reef sound, respectively. Moreover, larvae of $C$. citrinellus are repelled by barrier reef sound, whereas larvae of A. triostegus are neither attracted nor repulsed by both types of sounds (Parmentier et al., 2015). Taken together, these observations seem to indicate that describing the acoustic properties of the different coral reef habitats as average power spectra might not be appropriate to predict whether or not coral reef fish species could use the acoustic cue to find their way home.

\section{Conclusion}

As a whole, this study contributes to expand the knowledge about the hearing abilities of coral reef fishes at early life stages. Our results showed significant differences in detection abilities among fish species that are not phylogenetically related, suggesting that the establishment of their capabilities is not necessarily related to the reef conquest. The examination of detection abilities within species revealed that some of them exhibit size-related variations. Our audiograms also indicated that detection abilities can vary among fish families in terms of AEP thresholds and frequency range.

\section{Acknowledgements}

The authors are greatly indebted to the anonymous reviewers for their insightful comments and interesting criticism of the original version of the manuscript. This research was supported by the Belgian National Fund for Scientific Research (F.R.S.-FNRS) granted to L. Berten (no. FRIA 1.E096.10). [SW]

\section{References}

Barth, P., Berenshtein, I., Besson, M., Roux, N., Parmentier, E., Banaigs, B., Lecchini, D., 2015. From the ocean to a reef habitat: How do the larvae of coral reef fishes find their way home? A state of art on the lastest advances. Life Environ. 65, 91-100.

Bertucci, F., Parmentier, E., Berten, L., Brooker, R.M., Lecchini, D., 2015. Temporal and spatial comparisons of underwater sound signatures of different reef habitats in Moorea Island, French Polynesia. PLoS One 10, 9.

Braun, C.B., Grande, T., 2008. Evolution of peripheral mechanisms for the enhancement of sound reception. In: Webb, J.F., Fay, R.R., Popper, A.N. (Eds.), Fish Bioacoustics vol. 32 Springer, New York, pp. 99-144.

Capser, B.M., Mann, D.A., 2006. Evoked potential audiograms of the nurse shark (Ginglymostoma cirratum) and the yellow stingray (Urobatis jamaicensis). Environ. Biol. Fishes 76, 101-108.

Colleye, O., Ovidio, M., Salmon, A., Parmentier, E., 2013. Contribution to the study of acoustic communication in two Belgian river bullheads (Cottus rhenanus and $C$. perifretum) with further insight into the sound-producing mechanism. Front. Zool. 10,71 .
Coombs, S., Popper, A.N., 1979. Hearing differences among Hawaiian squirrelfish (family Holocentridae) related to differences in the peripheral auditory system. J. Comp. Physiol. 132, 203-207.

Corwin, J.T., Bullock, T.H., Schweitzer, J., 1982. The auditory brainstem response in five vertebrate classes. Electroencephalogr. Clin. Neurophysiol. 54, 629-641.

Dufour, V., Galzin, R., 1993. Colonization patterns of reef fish larvae to the lagoon at Moorea Island, French Polynesia. Mar. Ecol. Prog. Ser. 102, 143-152.

Egner, S.A., Mann, D.A., 2005. Auditory sensitivity of sergeant major damselfish Abudefduf saxatilis from post-settlement juvenile to adult. Mar. Ecol. Prog. Ser. 285, 213-222.

Higgs, D.M., Radford, C.A., 2013. The contribution of the lateral line to 'hearing' in fish. J. Exp. Biol. 216, 1484-1490.

Kenyon, T.N., 1996. Ontogenetic changes in the auditory sensitivity of damselfishes (pomacentridae). J. Comp. Physiol. A 179, 553-561.

Kenyon, T.N., Ladich, F., Yan, H.Y., 1998. A comparative study of hearing ability in fishes: the auditory brainstem response approach. J. Comp. Physiol. A 182, 307-318.

Ladich, F., Fay, R.R., 2013. Auditory evoked potential audiometry in fish. Rev. Fish Biol. Fish. 23, 317-364

Lecchini, D., 2005. Spatial and behavioural patterns of reef habitat settlement by fish larvae. Mar. Ecol. Prog. Ser. 301, 247-252.

Lecchini, D., Polti, S., Nakamura, Y., Mosconi, P., Tsuchiya, M., Remoissenet, G., Planes, S., 2006. New perspectives to aquarium fish trade. Fish. Sci. 72, 40-47.

Leis, J.M., 1991. The pelagic phase of coral reef fishes: Larval biology of coral reef fishes. In: Sale, P.F. (Ed.), The Ecology of Fishes of Coral Reefs. Academic Press, San Diego, pp. $183-230$

Leis, J.M., Lockett, M.M., 2005. Localization of reef sounds by settlement-stage larvae of coral-reef fishes (Pomacentridae). Bull. Mar. Sci. 76, 715-724.

Leis, J.M., McCormick, M.I., 2002. The biology, behavior, and ecology of the pelagic, larval stage of coral reef fishes. In: Sale, P.F. (Ed.), Coral Reef Fishes: Dynamics and Diversity in a Complex Ecosystem. Academic Press, San Diego, pp. 171-200.

Leis, J.M., Carson-Ewart, B.M., Cato, D.H., 2002. Sound detection in situ by the larvae of a coral-reef damselfish (Pomacentridae). Mar. Ecol. Prog. Ser. 232, 259-268.

Leis, J.M., Carson-Ewart, B.M., Hay, A.C., Cato, D.H., 2003. Coral-reef sounds enable nocturnal navigation by some reef-fish larvae in some places and at some times. J. Fish Biol. 63, 724-737.

Mann, D.A., Casper, B.M., Boyle, K.S., Tricas, T.C., 2007. On the attraction of larval fishes to reef sounds. Mar. Ecol. Prog. Ser. 338, 307-310.

Myrberg Jr., A.A., Fuiman, L.A., 2002. The sensory world of coral reef fishes. In: Sale, P.F. (Ed.), Coral Reef Fishes: Dynamics and Diversity in a Complex Ecosystem. Academic Press, San Diego, pp. 123-148.

Parmentier, E., Colleye, O., Mann, D.A., 2009. Hearing ability in three clownfish species. J. Exp. Biol. 212, 2023-2026.

Parmentier, E., Berten, L., Rigo, P., Aubrun, F., Nedelec, S., Simpson, S.D., Lecchini, D., 2015. The influence of various reef sounds on coral fish larvae behaviour. J. Fish Biol. 86, $1507-1518$

Simpson, S.D., Meekan, M.G., McCauley, R.D., Jeffs, A., 2004. Attraction of settlement-stage coral reef fishes to reef noise. Mar. Ecol. Prog. Ser. 276, 263-268.

Sisneros, J.A., Popper, A.N., Hawkins, A.D., Fay, R.R., 2016. Auditory evoked potential audiograms compared with behavioral audiograms in aquatic animals. In: Popper, A.N., Hawkins, A.D. (Eds.), Effects of Noise on Aquatic Life IIAdvances in Experimental Medicine and Biology vol. 875. Springer Science + Business Media, New York, pp. 1049-1056.

Smith, W.L., Webb, J.F., Blum, S.D., 2003. The evolution of the laterophysic connection with a revised phylogeny and taxonomy of butterflyfishes (Teleostei: Chaetodontidae). Cladistics 19, 287-306.

Tavolga, W.N., Wodinsky, J., 1963. Auditory capacities in fishes: pure tone thresholds in nine species of marine teleosts. Bull. Am. Mus. Nat. Hist. 126, 177-240.

Tolimieri, N., Jeffs, A., Montgomery, J., 2000. Ambient sound as a cue for navigation by the pelagic larvae of reef fishes. Mar. Ecol. Prog. Ser. 207, 219-224.

Tolimieri, N., Haine, O., Jeffs, A., McCauley, R., Montgomery, J., 2004. Directional orientation of pomacentrid larvae to ambient reef sound. Coral Reefs 23, 184-191.

Tricas, T.C., Boyle, K.S., 2015. Sound pressure enhances the hearing sensitivity of Chaetodon butterflyfishes on noisy coral reefs. J. Exp. Biol. 218, 1585-1595.

Webb, J.F., 1998. Laterophysic connection: a unique link between the swim bladder and the lateral-line system in Chaetodon (Perciformes: Chaetodontidae). Copeia 4, 1032-1036.

Webb, J.F., Smith, W.L., 2000. The laterophysic connection in chaetodontid butterflyfish: morphological variation and speculations on sensory function. Philos. Trans. R. Soc. B 355, 1125-1129.

Webb, J.F., Smith, W.L., Ketten, D.R., 2006. The laterophysic connection and swim bladder of butterflyfishes in the genus Chaetodon (Perciformes: Chaetodontidae). J. Morphol. 267, 1338-1355.

Webb, J.F., Walsh, R.M., Casper, B.M., Mann, D.A., Kelly, N., Cicchino, N., 2012. Development of the ear, hearing capabilities and laterophysic connection in the spotfin butterflyfish (Chaetodon ocellatus). Environ. Biol. Fishes 95, 275-290.

Wright, K.J., Higgs, D.M., Belanger, A.J., Leis, J.M., 2005. Auditory and olfactory abilities of pre-settlement larvae and post-settlement juveniles of a coral reef damselfish (Pisces: Pomacentridae). Mar. Biol. 147, 1425-1434.

Wright, K.J. Higgs, D.M., Leis, J.M., 2011. Ontogenetic and interspecific variation in hearing ability in marine fish larvae. Mar. Ecol. Prog. Ser. 424, 1-13.

Wysocki, L.E., Codarin, A., Ladich, F., Picciulin, M., 2009. Sound pressure and particle acceleration audiograms in three marine fish species from the Adriatic Sea. J. Acoust. Soc. Am. 126, 2100-2107. 